\title{
“Los comunistas no somos subversivos!”. E1 PC y la dictadura militar argentina (1976-1983)
}

\author{
Natalia Casola
}

(UBA-Conicet)

En 1986, ante el XVI Congreso del Partido Comunista (PC), el Secretario General, Athos Fava, abría su informe con una autocrítica. Afirmaba que la línea sostenida por el partido durante la última dictadura, el apoyo "táctico" al gobierno del teniente general Jorge R. Videla, había resultado de la confusión entre el objetivo estratégico de ganar a una parte de las Fuerzas Armadas para la revolución y el error "táctico" de creer que en ese momento era posible. Esta opinión, elevada a explicación oficial, presentó la conducta del partido como un "desvío" dentro una trayectoria histórica consecuentemente revolucionaria. ¿Era suficiente como explicación?

Desde entonces, las narrativas oscilaron entre el relato oficial y la versión construida por los "detractores" del partido, según la cual fue la Unión Soviética (URSS), interesada en mantener los lucrativos vínculos comerciales con Argentina, la que impuso al PC la línea de apoyo al gobierno militar, e inclusive la que negoció el mantenimiento de la legalidad del partido. ${ }^{1}$ No obstante, de aceptar esta última lectura habría que admitir que el comunismo vernáculo carecía de poder para disponer su politica y que su dirección y su militancia eran apenas meros

1. Véase, Carlos Echague (1986); Jorge Brega (1990). Más recientemente Sofia Lamberto (2006). En efecto, durante los años de la dictadura las relaciones bilaterales entre la URSS y la Argentina se fortalecieron tanto en términos políticos como económicos. Estos países actuaron juntos en el terreno de los foros internacionales para oponerse a la política exterior de los Estados Unidos y, en el plano comercial, suscribieron varios convenios de cooperación económica que beneficiaron enormemente a la burguesía argentina, exportadora de productos primarios. Esta investigación no desecha la opinión según la cual estos vínculos favorecieron la posición del PC vernáculo frente a la dictadura militar. No obstante, toma distancia de estos primeros trabajos, elaborados por intelectuales maoístas en el marco de una polémica más amplia, y por tanto diferente a la sostenida aquí, cuyo eje consistía en demostrar la transformación de la URSS en una potencia "socialimperialista". Para el maoísmo, el principal problema era que el PC se había subordinado a los soviéticos y que sostenian una "degeneración revisionista" cuyo inicio se remontaba a fines de los años 50. 
reproductores de una línea relativamente ajena a ellos (véanse Gilbert, 1994, y Campione, 1996 y 2005). Sin embargo, cuando se analiza la cuestión con mayor detenimiento, aparecen elementos que permiten cuestionar esta interpretación. La línea partidaria, tal como se presentó en 1976, se mantuvo inalterada hasta 1982 y con esa línea amplió su base militante. Tal manifestación de adhesión no puede explicarse solamente por pura disciplina partidaria, aunque ésta jugó un papel, y pone en evidencia que las definiciones politicas no eran extrañas a los militantes. Ciertamente, el acuerdo con la línea no fue absoluto y dio a lugar a varias situaciones de disconformidad; sin embargo, en la base de la formación política de los comunistas existian elementos que explican por qué el "apoyo" táctico no cayó como rayo en cielo sereno. En consecuencia, esta investigación sostiene que las raíces de la línea de apoyo "táctico" al gobierno de Videla deben buscarse en la evolución histórica de la propia política del partido. Dicho de otra manera, la orientación del PC en 1976 era la derivación más extrema de una política construida en base a la estrategia de revolución por etapas y la táctica de Frente Democrático Nacional: "antioligárquico, antiimperialista y pro paz, de todas las fuerzas progresistas y patrióticas" (Codovilla, 1964: 91), que el partido sostenía desde 1928 y que terminó de explicitarse a partir de 1935.

De acuerdo con el etapismo, en los países oprimidos era posible separar la etapa de la revolución democrática de la revolución socialista. Por lo tanto, en los países "atrasados" o "semifeudales", la tarea de los comunistas consistía en impulsar la etapa de la revolución democrática: desarrollar el capitalismo, introducir la reforma agraria, fortalecer la burguesía nacional y el crecimiento del proletariado: "No se trataba, en la presente etapa de su desarrollo, de combatir al capitalismo en general, sino al imperialismo y la oligarquía terrateniente y financiera" (Fava, 1983: 34).

La concepción de revolución democrática, convertida en objetivo estratégico, fue complementada con la política de "frente popular antifascista" o alianza con sectores de la burguesía "progresista" que, por esta vía, era transformada en el sujeto directivo de la revolución junto a una clase obrera escasamente desarrollada y a la espera de su turno en la historia. De esta manera, el PC elaboró un programa que, por sus propios fines, conducía a una política de alianzas con sectores de la burguesía considerados "progresistas". La búsqueda del "progresismo" abarcaba a todos los sectores, lo que incluía a las Fuerzas Armadas, ya que el comunismo postulaba la necesidad de la intervención política de los uniformados y, por esa razón, la defensa de la democracia en teoría no era contradictoria con la posibilidad de apoyar a un gobierno militar.

Pero la búsqueda del "progresismo" los había conducido a sostener 
una política de alianzas sumamente errática. Y esto era así porque los límites que separaban al "progreso" de la "reacción" eran tan difusos que bien podian ser intercambiables de acuerdo con la coyuntura. Los mismos que en un momento eran caracterizados como "democráticos", "progresistas" o simplemente "menos malos" podian luego caer en la categoría opuesta. ${ }^{2}$

En los años del último gobierno peronista (1973-1976), el PC comenzó a advertir que la derecha crecía en el Cono Sur alentada por el imperialismo norteamericano. En su visión, el golpe militar en Chile era la prueba de lo que podía suceder en Argentina si los sectores "progresistas" y "democráticos" no se unían para disipar los nubarrones. La lección extraída de Chile era clara: la responsabilidad de la caída de Allende recaía sobre la llamada "ultraizquierda" que no había sabido entender el peligro que se avecinaba y había exigido más de lo que era posible. Por analogia, a fines de 1973, el PC argentino optaba por denunciar a la "ultraizquierda" y desechaba la posibilidad de resolver la crisis política mediante un proceso revolucionario. Así, renacía la ya propuesta en otras coyunturas "convergencia cívico militar", un programa de "unidad nacional" para evitar el desplome del gobierno peronista. Y cuando fue evidente que esto no era posible, fue reemplazada por la consigna de

2. Durante los años 70 el PC ocupó un lugar importante en la izquierda argentina. Aunque en las décadas pasadas había sido desplazado por el peronismo del lugar de dirección política del movimiento obrero y la emergencia de la "nueva izquierda" disputaba con éxito su papel como representante de la izquierda revolucionaria, en ese proceso el PC se consolidó en otro lugar: el de la izquierda reformista. Justamente, eran las posiciones no ultimatistas lo que atraía a los nuevos militantes. La lucha por mejoras en los lugares de trabajo, la defensa de la democracia y una promesa de socialismo cuya garantía era la lejana Unión Soviética ofrecían una alternativa de izquierda que, al menos en lo inmediato, rechazaba la utilización de la violencia. Aunque el PC nunca se destacó por su peso electoral (en 1973 accedió a dos bancas de diputados por su participación en la Alianza Popular Revolucionaria), su presencia en fábricas, universidades y barrios del país era importante. Para componernos una idea debemos pensar que, hacia 1976, el número de militantes rondó los 15.000, un número nada desdeñable para un partido de izquierda. Además, el PC promovía el desarrollo de varias organizaciones que funcionaban como instancias de encuadramiento intermedio. Éstas podían ser de tres tipos: 1) agrupaciones ligadas directamente al partido, por ejemplo el Movimiento de Orientación Reformista (MOR) en la universidad y el Movimiento de Unidad y Coordinación Sindical (MUCS) en los sindicatos; 2) organizaciones que recibian el impulso y orientación del PCA pero que eran concebidas como espacios plurales, por ejemplo la Liga Argentina por los Derechos del Hombre (LADH), la Unión de Mujeres Argentinas (UMA), el Idisher cultur farband, Federación de Entidades Culturales Judias de la Argentina (ICUF) y la Unión de Productores Agrarios de la República Argentina (UPARA); 3) comisiones de solidaridad, por ejemplo la Coordinadora del Movimiento de Ayuda a Chile (COMACHI) o el Movimiento Argentino de Solidaridad Argentina con Vietnam. 
"gobierno cívico militar", lo que, en la práctica, implicaba proponer el reemplazo del gobierno por uno nuevo que, no cabía dudas, debía incluir a los militares "profesionalistas", los mismos que desde agosto de 1975 respondian al mando del General Videla. Como puede verse, un horizonte siempre peor podia esperar a los argentinos si no se unian defensivamente, y esta manera de interpretar la realidad fue creando las condiciones de posibilidad para la línea asumida a partir del 24 de marzo de 1976 y se transformó en la matriz desde la cual explicaron la defensa de Videla durante toda la dictadura.

En lo que sigue de este artículo nos detendremos en los fundamentos de la política del partido y en las formas de traducción práctica de la línea. El objetivo es mostrar el proceso de adaptación concreta del conjunto del partido a las condiciones impuestas por la dictadura: ¿por qué el Partido Comunista consiguió mantener la legalidad partidaria? ¿Qué ventajas otorgaba? ¿Qué implicaba militar en el PC en aquellos años? ¿Qué actividades realizaban? ¿Eran sostenidas por la militancia? En relación a este último aspecto, interesa mostrar algunas aristas del funcionamiento interno del partido para comprender por qué, a diferencia de lo que ocurrió en otros momentos de la historia, durante este periodo no hubo rupturas, fraccionamientos, ni serias críticas a la posición oficial. Este último aspecto se desarrolla especialmente en el convencimiento de que, junto a la formación política basada en un fuerte pragmatismo y posibilismo, el examen de las formas de construcción partidaria fundadas en las prácticas estalinistas ${ }^{3}$ permiten comprender más cabalmente por qué la línea partidaria pudo sostenerse durante tanto tiempo y polemizar tanto con la postura que reduce los posicionamientos del PC a los mandatos de la URSS, como con la explicación oficial que aísla la orientación asumida desde 1976 de la trayectoria histórica del partido.

\section{"Democracia avanzada o dictadura pinochetista"}

Ayer, el 24 de marzo, las fuerzas armadas depusieron a la presidente María Estela Martínez reemplazándola por una Junta Militar integrada por los comandantes de las tres armas. No fue un suceso inesperado. La situación había llegado a un límite extremo [...] La movilización de tropas del 24 de marzo había sido precedida de una intensa campaña que reclamaba "rectificar el rumbo". Efectivamente, era necesario y urgente

3. Las formas estalinistas de construcción partidaria refieren al personalismo, la obsecuencia hacia la dirigencia, la anulación de la polémica interna, la repulsa por las disidencias entendidas invariablemente como potencialmente destructivas y la sistemática lectura de la realidad de manera que confirmara la línea oficial. 
cambiar de rumbo [...] El Partido Comunista siempre se pronunció contra los golpes de estado. La experiencia indica que desde 1930 los golpes de estado tuvieron por objeto defender el latifundio improductivo y aumentar el grado de dependencia del país. Esta vez ¿'se romperá esa nefasta tradición? ${ }^{4}$

Efectivamente, la dirección nacional del Partido Comunista de Argentina pensaba que el gobierno militar encabezado por el teniente general Jorge R. Videla podía romper la "nefasta tradición" y pacificar el país, asolado por el terrorismo de "ambos signos". No hubo idas y venidas en la caracterización:

...lo que está en juego es la conquista de una democracia avanzada o el pinochetismo. Esos dos proyectos enfrentados conviven todavía dentro del proceso abierto por la Junta Militar. Un sector relevante del gobierno y de las Fuerzas Armadas, que incluye en primer lugar al propio presidente de la República, reitera casi cotidianamente que es su propósito erradicar el terrorismo, de cualquier signo, para consolidar la paz y la seguridad teniendo como objetivo prioritario la revitalización de las instituciones y el retorno a la democracia auténticamente representativa, republicana y federal [...] El otro sector, obnubilado por un odio irracional, de raíz fascista, se propone un baño de sangre generalizado. Con el argumento de que la guerra contra la subversión se debe extender a un espectro más amplio que el delimitado por el terrorismo ultraizquierdista, tiene el objetivo de perseguir a cualquier institución o ciudadano que sustente una ideología o simplemente una opinión, democrática, progresista... ${ }^{5}$

Desde entonces, la orientación del partido se resumía en lo siguiente: la defensa "táctica" del gobierno del general Videla para frenar las ambiciones de los sectores "pinochetistas". ${ }^{6}$ En su análisis, la principal

4. "Los comunistas y la nueva situación argentina. Declaración del Partido Comunista", en Resoluciones y Declaraciones. Año 1976/1977, Buenos Aires, Fundamentos, 1978, pp. 10-11.

5.Gerónimo Arnedo Alvarez, "Carta con motivo de fin de año", 20 de diciembre de 1976, en Resoluciones y Declaraciones Año 1976/ 1977, Buenos Aires, Fundamentos, 1978, pp. 27-28.

6.¿Quiénes eran los "pinochetistas" y quiénes los moderados en el análisis del PCA? Si exceptuamos los altos cargos militares, la división entre moderados y pinochetistas era mucho más ambigua de lo que prima facie la firmeza de su orientación política sugería. Entre los "pinochetistas" aparecía claramente en primer lugar Luciano Benjamín Menéndez, comandante del III Cuerpo de Ejército. Luego se mencionaba 
diferencia entre ambas facciones radicaba en el alcance que daban a los planes represivos. Para evitar la imposición del "pinochetismo" era necesario que el nuevo gobierno fuera capaz de neutralizar el accionar de las bandas terroristas tanto de derecha como de "ultraizquierda". Estas últimas, con sus "provocaciones", debilitaban al gobierno y abrian el camino a una "dictadura". Por esa razón, el PC se proclamaba enemigo del "terrorismo de ambos signos". ${ }^{7}$ Así, se dejaba en claro que el gobierno militar no constituía una dictadura, sino un "proceso" abierto y disputado por dos tendencias principales. Del desarrollo de una u otra dependía su evolución hacia un régimen democrático o hacia el "fascismo".

\section{La situación "legal" del partido}

Por el Decreto $\mathrm{N}^{\circ} 6$ la Junta Militar suspendió la actividad politica en todo el país, y por Decreto Ley del Poder Ejecutivo Nacional (PEN) 21.323 se advirtió que se reprimiría a quien no acatase dicha suspensión. ${ }^{8}$ Bajo esta ley recayó el conjunto del sistema político argentino incluido el Partido Comunista. Pero en junio de ese año se dictó la Ley 21.322 , por la que se disolvian y/o declaraban ilegales numerosas organizaciones politicas, sindicales y estudiantiles peronistas y marxistas, y en esa ocasión, el PC no estuvo incluido. ${ }^{9}$ Esta situación constituía un

a Carlos Guillermo Suárez Mason, comandante del I Cuerpo; Osvaldo Azpitarte, comandante del V Cuerpo, y Acdel Vilas, quien había estado a cargo del Operativo Independencia y posteriormente, desde 1976, actuó como segundo comandante del V Cuerpo. Finalmente, Eduardo Massera también es incorporado al elenco pinochetista aunque con posterioridad. Entre los "moderados" se encontraba el presidente, Jorge Rafael Videla, y Roberto Eduardo Viola, desde agosto de 1975 Jefe del Estado Mayor. También el general de división José Rogelio Villarreal, quien entre febrero y abril de 1976 fue jefe de operaciones del Estado Mayor General del Ejército y luego jefe del Área 311, cuya jurisdicción abarcaba la provincia de Córdoba. Posteriormente, pasó a desempeñarse en el Estado Mayor General del Ejército como jefe de personal, por lo que tuvo responsabilidad en todos los Centros Clandestinos de Detención (CCD) que dependian del Comando en Jefe del Ejército y en el accionar delictivo del personal de la fuerza. También dentro del III Cuerpo consideraban "moderado" a Reynaldo Benito Bussi, a pesar de haber estado alineado con la facción de Menéndez.

7. “ßBasta de violencia!”, Movimiento Obrero, $\mathrm{N}^{\circ}$ 2, 1 de julio de 1976. El periódico del PC adoptó varios nombres a lo largo de este periodo. Movimiento Obrero fue utilizado desde junio de 1976 hasta septiembre de 1977 cuando tomó el nombre Trabajo.

8. El Decreto Ley 21.277 suspendía "las previsiones y franquicias otorgadas oportunamente" a los partidos políticos. Aunque todas estas leyes son en realidad decretos leyes dictadas por el PEN, a los fines de simplificar en adelante se las denominará "ley".

9. Fueron prohibidos el Partido Socialista de los Trabajadores (PST), Política Obrera (PO), Partido Obrero Trotskista (POT), Partido Comunista Revolucionario (PCR), y el 
hecho inédito y les permitió obtener varias prerrogativas. Entre otras cosas, pudieron ampararse en la Ley 21.699 sancionada en diciembre de 1977 que establecía la prórroga en los mandatos de las autoridades partidarias. Este hecho supuso una enorme ventaja y permitió la supervivencia de la organización y su aparato. Posibilitó que el partido realizara una cantidad de presentaciones ante diferentes organismos públicos, firmadas por los propios apoderados que podían hacer uso de la personería jurídica. Además, en todas las provincias, delegaciones del partido pudieron presentarse habitualmente en los cuarteles militares y dependencias oficiales para reclamar por cesantías, detenciones y secuestros, o acercar propuestas sobre los más variados temas.

También en el plano de las organizaciones de masas el PC consiguió que algunas de aquellas que orientaba se mantuvieran legales. En estos casos, además, podían explotar la naturaleza "reivindicativa" de las mismas. Las motivaciones religiosas, culturales o de género las ayudaban a sortear con mayor facilidad las posibles acusaciones de predicamento político. A modo de ejemplo, el caso de la Unión de Mujeres Argentinas (UMA), ${ }^{10}$ ilustra cómo las militantes utilizaban el imaginario social dominante en torno a las mujeres y la supuesta inclinación "natural" hacia el amor y la protección de la familia para reclamar sobre diversas cuestiones. Reivindicaciones sociales como leche para los niños, viviendas para las familias, ropa para los inundados o la paz entre pueblos hermanos podian ser presentadas como demandas "femeninas" y así sortear la represión y la censura. No hubo tanta "suerte" en relación al movimiento obrero y estudiantil. ${ }^{11}$ Allí, la decisión de la dictadura fue disciplinar sin contemplaciones y advertir al partido que, si no emprendian una

Partido Comunista Marxista Leninista (PCML), además de las organizaciones armadas que fueron declaradas ilegales.

10.La UMA fue fundada el 17 de julio de 1947 con la idea de retomar la experiencia de la Junta de la Victoria durante la Segunda Guerra Mundial. A su vez, la UMA era miembro de la Federación Democrática Internacional de Mujeres (FDIM), también creada en el contexto de la segunda posguerra como parte del proyecto de los países socialistas para disputar ideológicamente a los Estados Unidos la influencia ideológica en el mundo occidental. El programa de la UMA articulaba dos tradiciones bien definidas. Por un lado, retomaba el pliego de reivindicaciones confeccionado a comienzos del siglo por las corrientes obreras, especialmente el socialismo, en cuanto a exigir al Estado la reglamentación del trabajo femenino y la igualdad salarial con los hombres. Por el otro, continuaba con la lucha iniciada por las primeras sufragistas haciendo eje en las reivindicaciones femeninas en tanto ciudadanas.

11. Por la Ley 21.325 quedaron ilegalizados el MUCS y el MOR, que actuaba en el espacio estudiantil universitario; también se proscribió a la COMACHI, al Movimiento Argentino de Solidaridad Argentina con Vietnam, a la UPARA y al Encuentro Nacional de los Argentinos (ENA). En todos estos ámbitos el PC tenía una fuerte participación. 
rápida retirada, sus militantes también caerian en las generales de la ley. Pero este trato desigual ponía de relieve el doble filo de los planes de la Junta Militar, que necesitaba contrapesar las prácticas genocidas con una política de tolerancia hacia la actividad de determinados partidos y organismos político-comunitarios. El funcionamiento parcial del espacio público permitía recrear, de cara a la opinión pública nacional e internacional, una imagen de "normalidad" que les facilitaba la reunión de las adhesiones. Además, es posible pensar que, para la Junta Militar, el apoyo del PC era importante y podía reportar beneficios superiores a los que obtenían de las organizaciones de derecha. Que las expresiones de aliento provinieran de un partido político de izquierda ayudaba a consolidar una imagen de pluralidad y diálogo. ${ }^{12}$

Sin embargo, el cálculo político no tuvo una traducción mecánica en la aplicación del sistema de terror, y el alcance del plan "antisubversivo" fue interpretado de acuerdo a las realidades regionales. Así, la autonomía relativa ganada por los comandantes de cuerpo, de zona, subzona y hasta de campos de concentración; las rivalidades inter e intra fuerzas explican por qué, en determinadas provincias, el PC fue atacado duramente y en otras recibió un trato amistoso. En líneas generales, puede advertirse que la "sociedad" política que estableció la dirigencia del partido con el videlismo se tradujo en un bajo nivel de represión hacia el partido, si se lo compara con los planes de exterminio reservados para el resto de la izquierda peronista y marxista, armada y no armada. ${ }^{13}$ No obstante, la propia interna de las Fuerzas Armadas influyó en el comportamiento represivo hacia el PC. En efecto, en las provincias bajo la jurisdicción del general "pinochetista" Luciano Benjamín Menéndez, el comunismo fue fuertemente reprimido. ${ }^{14}$ Este comportamiento contrasta con las

12. Véase, por ejemplo, las declaraciones de Videla al periodista Ceferino Reato (2012: 262)

13. Entre 1973 y 1979 se produjeron 154 casos de asesinatos y desapariciones de militantes comunistas. Los años posteriores no registraron nuevos casos. Entre 1973 y octubre de 1975, momento en que se generalizó el Operativo Independencia a todo el país, se registraron 16 víctimas y, entre octubre de 1975 y 1979, el número ascendió a 136, de las cuales más de la mitad fue asesinada o desaparecida en 1976 y 1977 (Casola, 2012).

14. El $31 \%$ de los casos de víctimas militantes del PC se produjeron en la Zona III, especialmente en las provincias de Córdoba y Jujuy. Casi la totalidad de esos casos refiere a miembros de los comités provinciales, referentes muy conocidos o, como sucedió en Córdoba, miembros del aparato militar. Por su parte, la Zona I concentró casi el 44\% de los casos. Sin embargo, al cruzar los datos con las historias particulares, surge una fuerte presencia de víctimas cuya militancia se desarrollaba en el movimiento obrero y estudiantil y, en muchos casos, los secuestros se produjeron en el marco de operativos represivos dirigidos contra determinada fábrica o facultad (Casola, 2012). 
otras zonas del país donde la aplicación de la represión fue desigual y respondía a diversas causas que, la mayoría de las veces, no se vinculaban a la militancia comunista de las víctimas.

Para la dirigencia nacional del PC el mantenimiento de la legalidad era un elemento central que servía como argumento para rebatir las posibles acusaciones de "subversión". La lógica era la siguiente: el partido era legal porque no era "subversivo"; por ende, debía quedar al margen de la represión. En comitivas oficiales o particulares, cuando los familiares y compañeros realizaban gestiones a favor de los presos y secuestrados del partido, invariablemente presentaban la militancia comunista como una prueba de la "inocencia" de las víctimas. Esta estrategia fue con frecuencia exitosa. Varios informes dan cuenta de las numerosas ocasiones en que las delegaciones del partido consiguieron revertir situaciones de represión. Tomemos algunos ejemplos:

Informe del camarada Isidoro sobre el viaje a San Luis. [No especifica mes. Presumiblemente abril de1976]

Algunas experiencias ocurridas en la provincia ayudaron a contar con ciertos elementos y argumentos políticos para mostrar la correcta posición del Partido. Por ejemplo: [...] Frente a la detención de una compañera de la FJC se entrevistó al Tte. Coronel Moreno del Regimiento 141, de San Luis. Ante él, la madre insistió que ella y su hija detenida eran comunistas y que no tenían vinculación con extremistas. Éste dijo que conocía la posición del Partido y que iba a verificar. Si realmente no tenía vinculación con los extremistas sería puesta en libertad cosa que ocurrió. [...] Alrededor de esta y otras experiencias locales los camaradas se esfuerzan por hacer comprender al conjunto de los afiliados la táctica del Partido y disponerse a abordar la actividad con las Fuerzas Armadas. ${ }^{15}$

El informe era categórico, los dirigentes y familiares debían actuar con serenidad y explicar cuál era la posición del partido. Una vez que las fuerzas de seguridad actuantes comprobaran que no existían vínculos con la guerrilla serian puestos en libertad, o al menos su situación se aclararía. Pero además, las gestiones exitosas servían para justificar la línea internamente. Según el informe, gracias a estas experiencias locales, los camaradas podian ilustrar ante las bases las diferenciaciones que establecía la línea y "hacer comprender al conjunto de los afiliados la táctica del Partido".

15. Informe al CC sobre la situación en San Luis [¿́abril?] 1976. Carpeta "Informes de las provincias.1976-1977", Legajo 93, Archivo Histórico del PCA. En adelante este material se citará como "Legajo 93". 
Una situación similar se registra en la provincia de Entre Ríos durante septiembre de 1976:

Concordia: el Jefe Militar de la zona que ordenó el "operativo costa" durante el cual fue detenido un camarada y secuestrado el mimeógrafo del Comité local fue entrevistado por el Partido y se expresó así: "yo sé que los comunistas no están en la subversión". Puso en libertad al detenido y sobre el mimeógrafo le dijo al compañero que es médico: "pero Dr., si el mimeógrafo lo hubiera tenido en su consultorio no pasaba nada. Pero Uds. lo tenían en un ranchito misterioso junto con el revólver".

Concepción del Uruguay: Del Comando de Ejército llamaron al secretario del Partido para "leerle una resolución". Se trataba de la devolución del local del Partido: "le entrego el local para el pago de impuestos" (risas) y a los efectos de la administración. Pidieron les informaran si les faltaba algo que "sería repuesto y que informarian a la policía para que no los molestaran". Que podían ir al local. "Pero no vayan 50 ". Y agregó lo siguiente: "Lindo choclo nos han dejado con esto de gobernar". "Queremos que las cosas sean justas". "El único problema es la subversión". ${ }^{16}$

El respeto de la legalidad dependía de la capacidad de acción de la militancia, pero también de la predisposición de las fuerzas militares locales. De los 500 secuestros de militantes del PC registrados hasta 1979 , cerca de 370 fueron liberados. ${ }^{17}$ Esta cifra sugiere que la capacidad del partido para interceder por sus militantes era significativa. No obstante, las prerrogativas que valian para buena parte del país quedaban prácticamente sin efecto en el Tercer Cuerpo de Ejército y, más especialmente, en Córdoba y Jujuy. Los informes de esas provincias indican que las delegaciones del partido se movian con mucha dificultad y sus gestiones no producian efecto alguno. Por ejemplo, un informe de Jujuy producido en 1976 tras una ola de represión decía:

Los camaradas han realizado una ofensiva de entrevistas. 1) Con Bulacios, que los recibió "muy bien". La conversación duró 2 horas, en su transcurso llamó a dos oficiales de "inteligencia". La tesis de Bulacios es que "el PC son iguales que ERP

16. Informe al CC sobre la situación en Entre Ríos, Legajo 93.

17. En ocasión de la visita de la CIDH, el PCA denunciaba el asesinato de 25 militantes y el secuestro de más de 500 afiliados, de los cuales, 105 continuaban desaparecidos. 
y Montoneros." Que persigue al Partido por ser los mayores difusores de la doctrina. El camarada secretario le dijo que "el gobierno nacional no lo cree así. No estamos proscriptos" y le entregó la resolución judicial sobre el Partido en la Capital Federal. Él se remitió al hecho de haber encontrado elementos de un curso realizado en Tucumán por un compañero...

El Coronel Bulacios finalmente amenazó "el problema es sencillo. Usted es hombre que yo respeto por su franqueza y porque es el único dirigente político que habla conmigo. Los informes sobre usted son buenos, pero si empieza a moverse por diversos lugares, yo actuaré, aquí en la ciudad usted puede moverse... pero nada de volantes y pintadas". ${ }^{18}$

Por otro lado, y sin negar que muchas gestiones fueran exitosas, las direcciones nacionales y provinciales del partido tendian a confiar en las Fuerzas Armadas, en las reuniones y en las informaciones que recibian. Esta confianza, reforzada por otros elementos como la fuerte tendencia por parte de los informantes a no contradecir la línea oficial, distorsionaba la realidad y los llevaba a cometer descuidos que algunas veces costaba la vida de los militantes.

\section{E1 dia después...}

El golpe de Estado del 24 de marzo de 1976 fue recibido sin sorpresa, pero la primera reacción que ocasionó fue temor y se tradujo en un repliegue espontáneo de la militancia, que se profundizó en los días que siguieron. Aunque nunca llegaron a ser deserciones masivas, la actividad mermaba porque la militancia se venía preparando para pasar a la clandestinidad ya que suponían que el golpe militar en Argentina sería similar al de Pinochet en Chile. Sin embargo, hemos visto que el dia 25 de marzo el Comité Central emitió un comunicado optimista: los "pinochetistas" habian quedado marginados de la conducción del "Proceso". La política del partido desde entonces debía consistir en defender al nuevo gobierno de las amenazas de estos sectores, sólo neutralizados coyunturalmente. En los dias subsiguientes, los decretos ley emitidos por el PEN reconfirmaron la orientación del Comité Central, y por esa razón dispusieron que la militancia mantuviera la actividad. Frente a los primeros hechos de represión, el partido responsabilizó a las bandas paraestatales heredadas del gobierno anterior o bien caracterizó que formaban parte de los planes "pinochetistas" para desestabilizar al presidente Videla. En cualquier caso había que esperar y, simultánea-

18. Informe al CC sobre la situación en Jujuy, Legajo 93. 
mente, presionar para que el gobierno tomara las riendas definitivas y pusiera coto a esa situación.

En ese clima, la necesidad de redistribuir responsabilidades, sobre todo entre los cuadros medios, comenzó a ser acuciante: según cifras oficiales, entre 1976 y 1978 fueron reubicados alrededor de tres mil militantes con el fin de readaptar la estructura a las nuevas condiciones. ${ }^{19}$

A partir de la semana siguiente al golpe, emisarios del Comité Central viajaron a todo el país para difundir la línea, llevar tranquilidad y recoger las primeras informaciones. El núcleo de la argumentación consistía en explicar que la "cuestión" no era con ellos, sino con la "ultra". La principal medida de seguridad, por lo tanto, consistía en evitar contactos con la guerrilla. Si algún militante era detenido, no debía resistirse; si era citado, debía acudir y, sobre todo, demostrar que pertenecía al Partido Comunista. ${ }^{20}$ De manera que los reajustes en la actividad debian hacerse de forma tal que no interrumpiera el trabajo cotidiano: los cuadros sindicales debían presentarse a trabajar, los estudiantes ir a sus facultades y los militantes barriales y de las organizaciones de masas, continuar con la planificación del desarrollo del partido en sus espacios de intervención. A puertas cerradas, los locales continuaron funcionando como centros de reunión y el periódico siguió apareciendo con diversos nombres.

Entre las actividades de mayor exposición política que siguieron realizándose, se contaban las visitas a los cuarteles militares y comisarías, a las que se hacian llegar las declaraciones y publicaciones del partido. $\mathrm{Al}$ respecto, cada regional llevaba un control estricto de esas visitas y de la evolución de los debates con los jefes militares. El propósito de estas reuniones era difundir la línea oficial, evitar que se confundiera al PC con una organización "subversiva" y elaborar una radiografia de la situación al interior de las Fuerzas Armadas y de seguridad, a fin de establecer quiénes eran "pinochetistas" y quiénes "moderados". Estas tareas, generalmente, eran llevadas a cabo por los responsables políticos del partido y de la FJC en cada regional.

Entre las actividades de menor exposición se contaban las visitas al "padrón" de simpatizantes y/o afiliados a los que se les vendía el periódico o se les pedían aportes financieros. La ventaja de este tipo de diligencias es que podían llevarse a cabo en casas particulares sin exponerse en público. También se realizaban pic-nics, fiestas, charlas, cumpleaños y asados que camuflaban el carácter político de las reuniones. Resulta notable que durante este periodo también se produjeran

19. "Problemas de organización", s/f, 1978.

20. Una excepción fue la tramitación de la salida al exilio a Bulgaria para el dirigente de la construcción Alberto Canelles. 
nuevas incorporaciones. Solamente entre 1976 y 1978 se efectuaron 2.974 nuevas afiliaciones en todo el país y, a pesar de que únicamente una minoría se incorporaba a la militancia activa, esta cifra no dejaba de ser elevada si se tienen en cuenta las condiciones políticas imperantes. ${ }^{21}$ Con todo, hasta 1980 predominó un doble movimiento por el cual muchos militantes desertaban pero eran compensados por el ingreso de otros nuevos, que veían en el PC un partido confiable, organizado y seguro. En los últimos años, la tendencia al crecimiento se profundizó, probablemente alentada por el comienzo de la crisis del régimen militar, la recomposición de las alianzas y del ciclo de movilización antidictatorial.

En suma, durante los primeros dos años el movimiento de adaptación del partido osciló entre "el mostrarse" y "el ocultarse" masivamente. Cuando se mostraban, lo hacian a la luz del día y para ser vistos por los militares. Cuando se ocultaban, era para desarrollar tareas de autoconstrucción. En cualquier caso, es dificil encontrar al PC en alguna actividad pública de abierta oposición al régimen militar. En el ámbito de los derechos humanos, su participación a través de la Liga Argentina por los Derechos del Hombre (LADH) consistía en organizar a los familiares, sin por eso denunciar la responsabilidad estatal por los secuestros y detenciones. Solo a partir de 1979, y en un contexto de crisis política y económica, el partido vuelve a formar parte de un movimiento de oposición, sin representar por eso su ala más radical, esta vez liderada por Madres de Plaza de Mayo, Familiares de Desaparecidos y Detenidos por Razones Políticas y una militancia de izquierda menos visible pero muy activa al interior de los organismos. ${ }^{22}$ No obstante, la presencia comunista en las movilizaciones obreras, estudiantiles y por los derechos humanos del último tramo de la dictadura no condujo a una revisión de la línea política. El llamado a la "convergencia cívico militar", cuya concreción en 1981 no parecía tan lejana, siguió siendo la principal propuesta del partido. Los levantamientos de Menéndez en 1979 y el derrocamiento de Viola a fines de 1981 ayudaron a reciclar los argumentos para continuar apostando al "mal menor" y renovar las esperanzas en el papel que pudiera cumplir la Multipartidaria. ${ }^{23}$

21. "Problemas de organización", s/f, 1978.

22. Familiares de Desaparecidos y Detenidos por Razones Politicas fue formado en septiembre de 1976 como una comisión impulsada por la LADH. Al poco tiempo, sin embargo, cobra tal envergadura que adquiere una fisonomía propia. Madres de Plaza de Mayo surge en abril de 1977 y cristaliza como organismo al calor de la búsqueda de los hijos desaparecidos y de la concurrencia a la Plaza de Mayo para exigir respuestas a la dictadura. Para ahondar en los debates políticos entre los organismos de derechos humanos y con la LADH en particular, véase Casola (2011).

23. El 14 de julio de 1981, a iniciativa del dirigente radical Ricardo Balbín, se reunie- 
Solamente la derrota de Malvinas echó por tierra la posibilidad de concretar un gobierno que incluyera a civiles y militares. Desde entonces, la reconversión de la línea fue costosa, porque estuvo acompañada por el descubrimiento, por parte de la militancia, de que su partido habia estado realmente en la vereda de enfrente.

\section{La disciplina partidaria}

Si bien la primera declaración del partido se produjo el día 25 de marzo, la mayoria de las provincias debieron esperar unos dias hasta tener copias en su poder. En ese lapso de tiempo, entre el golpe y el momento que conocieron la línea oficial, el análisis de la militancia en todo el país se disparó en varios sentidos. Aunque resulta difícil asir ese lapso de tiempo, algunos informes elaborados por los emisarios del Comité Central a las provincias, confeccionados dias o semanas después de producido el golpe en base a la información trasmitida por los responsables locales, ayudan a reconstruirlo.

Es importante aclarar que estos documentos describen la situación en las diversas provincias desde una óptica muy particular y que, en muchos casos, es probable que las tendencias al acuerdo con la línea hayan sido exageradas en el afán de confirmar la caracterización del Comité Central. Aun así, algunos de estos informes revelan muchos datos sobre la situación del partido en los distintos lugares.

En algunos casos, como los de las ciudades patagónicas de Comodoro Rivadavia, Trelew y la provincia de Santa Cruz, la posición del partido fue conocida de inmediato gracias a Radio Moscú.

Las direcciones se informaron de la primera declaración del CC sobre el golpe de Estado, a través de Radio Moscú que, según dijeron, se escucha muy bien en la Patagonia y actuaron desde los primeros momentos con esa orientación. ${ }^{24}$

ron los máximos dirigentes de los principales partidos politicos argentinos: Unión Cívica Radical (UCR), Partido Justicialista (PJ), Partido Intransigente (PI), Partido Demócrata Cristiano (PDC) y Movimiento de Integración y Desarrollo (MID) que decidieron constituir la Multipartidaria, una herramienta concebida para negociar con el régimen militar y acordar los términos de una transición que debía culminar en el llamado a elecciones y en la restauración de la democracia. En tal sentido, la Multipartidaria, no representaba la ruptura de las fuerzas civiles con el régimen militar; por el contrario, su objetivo era institucionalizar el diálogo que, hasta el momento, se habia desenvuelto por canales informales.

24. Informe al CC sobre la situación en Comodoro Rivadavia, Trelew y Santa Cruz, Legajo 93. 
También en Neuquén y Río Negro la información transmitida por Radio Moscú ayudó a que los responsables del partido se orientaran en la nueva situación.

Se reunieron por separado los dos secretariados provinciales a fin de recibir la información y discutir. En los dos casos las direcciones aprobaron la posición fijada por la dirección del Partido. La experiencia realizada por las organizaciones partidarias a partir del dia del golpe hasta ese momento, 30 de marzo, confirmaba la justeza de lo señalado alli acerca de las distintas corrientes y nuestra ubicación. A los compañeros les ayudó a ubicarse la propagación de Radio Moscú. ${ }^{25}$

Como se desprende de estos dos informes, el recibimiento de la línea era seguido por su aceptación. Inclusive "la experiencia realizada", en esos días, hasta el 30 de marzo, momento en que se escribía el informe, "confirmaba la justeza de lo señalado". Pero aunque la mayoría de los documentos sugieren que la línea era bien recibida por los responsables locales, otros advierten sobre las dificultades que aparecian cuando la línea era retransmitida hacia abajo. ¿No era el "pinochetismo" el que había dado el golpe de Estado?

En Neuquén... había un poco de confusión pues al haber planteado siempre nuestra posición contra el golpe de Estado, se pensó solo en una variante pinochetista del mismo. Hubo acuerdo. ${ }^{26}$

En la base militante intuitivamente se manifestaba cierto reparo en la defensa de los militares. Sin embargo, en el caso de Neuquén, a pesar de los problemas, el emisario afirma que igualmente "hubo acuerdo". Otros informes, en cambio, desarrollan mucho más las dificultades que se encontraban. Por ejemplo, el enviado a San Luis, el "camarada Isidoro", informa:

Constata el compañero los esfuerzos que hace el secretariado por llevar abajo las ideas del documento del CC del 25 del marzo y del anterior informe. La impresión del camarada informante es que el secretario provincial hace esfuerzos por interpretar el proceso que se inició el 24 de marzo, domina las ideas centrales y pese a las presiones de algunos sectores -especialmente después de conocer la plataforma Martínez de

25. Informe al CC sobre la situación en Neuquén y Rio Negro, Legajo 93. 26. Ibídem. 
Hoz- tratan de ayudar al conjunto del Partido a ubicarse correctamente. Los aspectos que más presionan son los cesantes en la administración pública, en ferroviarios y otros. Si bien algunos casos son reales, hay una especie de campaña psicológica tendiente a crear alarma y con ello presionar al Partido sobre su posición. ${ }^{27}$

Este último informe resulta interesante porque pone de relieve que la posición asumida por el partido no era la esperada ni la más probable para la militancia. Así, los "esfuerzos" del secretariado por retransmitir la linea eran contrapesados por las "presiones de algunos sectores". Aunque no determina cuáles eran esos sectores, el resto del informe deja entrever que era la propia realidad la que oponía motivos para cuestionar la línea. La confrontación con las cesantias, las detenciones y los secuestros desarmaba los argumentos del secretario del partido provincial. También los informes de Entre Ríos registraban problemas similiares:

Al cumplirse un mes del golpe se produce en Paraná, Concordia, Concepción del Uruguay y Diamante una ola de despidos y suspensiones en lugares de trabajo y estudio [...] Estos hechos obligaron a estar más cerca de todos los afiliados y a reiterar fundamentando lo mejor posible, no solo la justa posición táctica, sino al mismo tiempo ayudar a organizar diversas formas de movilizaciones. En esto último, no siempre fue fácil orientar la resistencia a esa ofensiva del pinochetismo y de otros elementos de derecha en el seno de las FFAA que gobiernan. [...] Por parte de algunos amigos y aliados comenzó a sentirse cierta presión en las filas del Partido que se caracterizaban en anti-Fuerzas Amadas. ${ }^{28}$

La misma situación se repetía en otros lugares del país. De manera que el encuadramiento con la posición oficial del partido no fue automático, y aunque no generó fraccionamientos -ni la situación política, ni la tradición partidaria favorecían las deliberaciones- las direcciones intermedias debieron esforzarse por alinear a las bases cuyas críticas comenzaban a extenderse.

En el Magisterio hay luchas, aquí todavía no se entiende a fondo la táctica producto de insuficiencias sectarias del responsable. Hay cesantes -no del Partido. Algunos dirigentes están

27. Informe al CC sobre la situación en San Luis, Legajo 93.

28. Informe al CC sobre la situación en Entre Ríos, 1976, Legajo 93. 
colaborando en el Consejo de Educación y en lugar de entender y ampliar esto, los critican como colaboracionistas. ${ }^{29}$

En este último caso, también de Chaco, se instaba a que los maestros del partido, a pesar del aumento de las cesantías, aceptaran que otros camaradas colaboraran en el Consejo de Educación. Las críticas que ocasionaba invariablemente eran desatendidas caracterizándolas como "tendencias antimilitaristas" o expresiones de "sectarismo". El problema siempre radicaba en la "insuficiente" comprensión por parte de los militantes.

En las provincias donde la represión se agravaba, la tendencia a cuestionar las definiciones políticas del CC se acrecentaba explícita o implícitamente mediante un repliegue de hecho. Así, el informante de La Rioja transmitía:

...la situación en la provincia es dificil. [...] El que dirige es Bataglia, hombre de Menéndez. [...] Se ha logrado crear un clima de terror; nadie se atiene a reclamar [...] La represión se expresa en la detención de más de 200 personas de las cuales 7 son compañeros del Partido; se producen casi a diario operativos rastrillo. [...] Esta situación se refleja en el Partido.

A opinión de la compañera informante en la provincia no se puede decir que exista el Partido sino un núcleo de afiliados al que hay que ayudar mucho para que puedan salir adelante en esta dificil etapa... El no funcionamiento partidario hace surgir discrepancias personales entre familiares y que asuman actitudes que no están bien, como por ejemplo llevar las Obras de Lenin a una casa donde fueron quemadas por temor. ${ }^{30}$

En este caso, la represión y el temor fueron más potentes que la voluntad de la dirección para mantener en funcionamiento la organización. Una situación similar registraba el emisario en Jujuy donde la represión al PC era particularmente intensa. ${ }^{31}$

Así, la línea oficial, por las prerrogativas obtenidas gracias al mantenimiento de la legalidad a nivel nacional, no contemplaba que en algunos lugares y/o espacios de militancia hubiese que tomar medidas especiales. Inclusive en las provincias "pinochetistas", es decir las que se encontraban bajo el mando del Tercer Cuerpo, las directivas para la militancia eran similares a las resueltas para el resto del país: establecer

29. Informe al CC sobre la situación en Chaco, 1976, Legajo 93.

30. Informe al CC sobre la situación en La Rioja, 1976, Legajo 93.

31. Informe al CC sobre la situación en Jujuy, 1976, Legajo 93. 
reuniones con las autoridades y con los partidos políticos, velar por el cumplimiento de la legalidad, realizar campañas financieras, distribuir los materiales del partido y movilizarse por las libertades democráticas y la libertad de los presos políticos. Las medidas de repliegue se tomaban solamente cuando la represión ya habia tocado la puerta. En estas encrucijadas, la iniciativa de los responsables locales era importante para poder preservar a los militantes que habian recibido advertencias. En algunos casos solicitaban la autorización al Comité Central para, por ejemplo, enviar fuera del país al amenazado $/ a,{ }^{32}$ pero en otros, actuaban por cuenta propia y organizaban el exilio de hecho. ${ }^{33}$

También el análisis de la situación de la militancia en el movimiento obrero y estudiantil pone de relieve que la legalidad del partido no era garantia suficiente para el desarrollo de la militancia. El primer problema que se presentaba a los delegados y/o dirigentes era la naturaleza misma de su actividad que los conectaba con militantes de otras organizaciones, muchas de ellas consideradas por la dictadura como "subversivas". ${ }^{34}$

De manera que, en los frentes de masas, los militantes comunistas quedaron expuestos a la represión. Por la naturaleza misma de las actividades gremiales o estudiantiles, realizaban actividades en conjunto con las organizaciones guerrilleras y de otras tendencias de la izquierda que se encontraban proscriptas. Así, en virtud de los planes de la dictadura, numerosos militantes comunistas fueron secuestrados confundidos con guerrilleros o porque los consideraban fuentes de información para llegar a ellos. Para muchos militantes del partido estas experiencias fueron reveladoras de la distancia que existía entre la línea y la realidad. A regañadientes o con cierta pasividad, a lo largo de aquellos años fue germinando en forma subterránea y atomizada un descontento hacia las posiciones oficiales, cuya potencia comenzó a vislumbrarse al finalizar la dictadura.

Pero a pesar de que varios entrevistados y documentos de la época dejan ver que las posiciones oficiales del partido generaban incomodidad, no hubo disidencias abiertas como en otros momentos de la historia del partido. Si históricamente el Partido Comunista no se había caracterizado precisamente por ser contemplativos con aquellos que manifestaban desacuerdos, mucho menos en un contexto signado por la censura y

32. Véase carta recibida desde Comodoro Rivadavia, 17-10-76, Legajo 93.

33. Véase Informe al CC sobre la situación en Santa Cruz, 1976, Legajo 93.

34. Ese fue el caso, por ejemplo, de Roberto Páez, delegado del frigorífico Swiff en Berisso. Cuando se produjo el golpe se encontraba de vacaciones en Mar del Plata luego de una situación familiar conflictiva que lo obligó a licenciarse en esa época del año. Al regresar a su casa los primeros días de abril lo esperaba un compañero del partido que le confirmó que podía volver a trabajar. En los primeros días de abril la Marina secuestra a Páez. 
el terror. Así, la actitud mayoritaria fue el abroquelamiento, llevando al extremo el hábito de encuadramiento acrítico con las posiciones de la dirección. El testimonio de "Fantu", militante de la juventud en la Zona Sur, resulta representativo del comportamiento que predominó:

Todos los que hicimos politica en la época de la dictadura, todos, llevamos la línea a pie juntillas, había excepciones... eh... que no se manifestaban tan... que no... la gente del frente militar tenía cuestionamientos... pero yo me entero después, porque era un frente totalmente cerrado. No había una cosa abierta, de cuestionamiento. Al menos, yo no lo viví y mis compañeros tampoco. Yo creo que hubo un estrechamiento de filas y se avanzó con eso. Eso es lo que yo viví y lo que me transmitió cada uno. Lo que yo viví fue eso. Todo el 79 , todo el 80 , todo el 81 y todo el $82 .{ }^{35}$

Inclusive Carlos Loza, que habia sido secuestrado en diciembre de 1976 y llevado a la ESMA, donde permaneció desaparecido hasta el 1 de enero de 1977, continuó militando en el partido sin abrir un juicio crítico respecto de las posiciones oficiales:

Yo seguí militando, me sacaron de este lugar y bueno... yo pedí colaborar en otro sector y me mandaron a acompañar a un compañero que iba a atender lo que era el campo, en Navarro.

PREGUNTA: ¿Y no entraste en crisis nunca con la línea de la convergencia cívico militar?

RESPUESTA: No, porque además no tenía otra forma de vincularme. Igual fueron dos o tres años donde todo era muy light. Pero era la organización en la que yo estaba. No era crítico, más bien era complaciente. La firmeza ideológica la adquirí después. Pertenecer al Partido Comunista no significaba que fuera un militante con ideología revolucionaria. Era un voluntarioso militante popular, pero de ahí a que ese militante tuviera una concepción revolucionaria había una distancia enorme. Entonces yo no estaba analizando eso. Lo que sí no llegué a entender nunca es por qué fuimos al local, cómo fui a parar ahí para reunirme. [...] ¡Porque habíamos caído en el local del Partido Comunista! Se depositaba mucha... la militancia depositaba mucha confianza en la dirigencia, en todas

35. Entrevista a Fantu (2009). 
las dirigencia hasta casi juzgándolas como infalibles. Porque eso también pasó en las demás fuerzas. ${ }^{36}$

También Carlos Zamorano, quien pasó por las cárceles argentinas entre 1974 y 1979, a pesar de haber sido víctima del régimen terrorista, continuó defendiendo las posiciones del partido: ${ }^{37}$

PREGUNTA: ¿Cuál era su opinión en ese momento respecto a la posición del partido bajo la dictadura de Videla?

RESPUESTA: Totalmente coincidente, en el fondo, filosóficamente como lo estoy hoy; [...] conozco que hay una profusa literatura en contra del Partido Comunista sin el más remoto derecho, haciendo un revisionismo histórico -como suele ser el revisionismo histórico- sin solvencia, sin sustento, sin conocimiento, en fin... que sustenta esencialmente que había cometido el partido comunista el siguiente error básico: es decir, hay que evitar el advenimiento del pinochetismo, cuando en realidad, Videla y Pinochet eran un solo corazón, se dice. Pero lo cierto es que Videla gobernó cuatro años casi todo el tiempo vestido de civil sin pistola y retirado del Ejército, mientras que Pinochet gobernó años incompartidamente, en una dictadura inmensa de la cual se pasó a una supuesta transición que no es tal, es más continuismo que transición hacia, dicen ellos, la democracia que no existe en este momento, etc., así que poner un signo igual entre los designios de los pinochetistas como puede ser Luciano Benjamín Menéndez en la Argentina, entre otros, y el videlismo es un exabrupto. ${ }^{38}$

El testimonio de Zamorano resulta interesante porque pone de relieve que, al menos públicamente, por encima de su experiencia personal con la represión, continuaba acordando con una concepción: la defensa del mal menor como mecanismo de salvaguardia politica en contextos adversos. Dicho de otro modo, el testimonio de Zamorano, por su defensa reciente de las posiciones sostenidas en la dictadura, personifica la coherencia de la lógica política del partido. Lógica que, despojada del

36. Entrevista a Carlos Loza (2012).

37. Carlos Zamorano se afilió al PCA el día 15 de diciembre de 1958. Fue miembro del comité provincial de Tucumán y apoderado del partido de la provincia. A fines de los años 90 pasó a integrar el Comité Central. Entre las numerosas defensas que llevó adelante en su vida profesional estuvo la de Roberto Santucho, principal dirigente del PRT.

38. Entrevista a Carlos Zamorano (2003). 
contenido moralmente reprochable que se le atribuyó posteriormente, expresaba una manera de interpelar y de actuar sobre la realidad.

En suma, las razones por las cuales la militancia comunista llevó adelante la linea del partido, aun cuando eran evidentes los planes genocidas, fueron diversas. ¿Acuerdo con la línea? ¿Pobreza en el análisis? ¿Instinto de conservación partidaria? ¿Hábito de encuadramiento? ¿Ausencia de posibilidades para plantear una deliberación interna? Todas estas preguntas pueden ser respondidas afirmativamente. La acumulación de disidencias fue un proceso larvado, subterráneo, cuyo potencial recién expresará su poder disolvente hacia el XVI Congreso de 1986 y los años que siguieron. Lo cierto es que entre 1976 y 1983 la clausura del debate interno como producto de la suspensión de la vida política potenció las formas de disciplina partidaria de corte estalinista y postergó la polémica para los años de la llamada "transición a la democracia".

$$
* * *
$$

El presente artículo examinó el papel del PC durante la última dictadura militar a partir de elementos poco explorados por la historiografia e intentó, explícitamente, apartarse tanto de la justificación oficial elaborada por el partido como de las explicaciones más conocidas centradas en el papel de la Unión Soviética.

En primer lugar, se subrayó la filiación histórica que existía entre las posiciones sostenidas por el partido a partir del golpe de Estado de 1976 y la estrategia de revolución democrática, y la herramienta del frente popular o Frente Democrático Nacional. ¿Dónde comenzaba y terminaba el sector "progresista", dónde el "reaccionario"? La laxitud, la imprecisión del planteo creaba la condición de posibilidad para la concreción de alianzas diversas, contradictorias, justificadas siempre en nombre de la defensa del progreso. Así, la calificación de "democrático" de cualquier sector social, politico, o de las fuerzas armadas funcionaba como argumento suficiente para apoyar sin matices a un actor político, cualquiera sea su lugar social o definición ideológica. Hacia 1975 el programa de "convergencia cívico militar", ya formulado en otras coyunturas, venía a plantear la necesidad de rescatar al gobierno peronista de su propio desplome y, cuando esta solución se mostró inviable, la consigna fue conservada con el argumento de evitar un mal peor, una "verdadera dictadura". Esa lectura fue la que se mantuvo inalterada en los años siguientes hasta que la derrota de Malvinas demostró que el final de la dictadura comenzaba a acercarse. Solo entonces el partido abandonó la propuesta de una normalización institucional que incluyera a los militares. 
En segundo término, este artículo expuso los argumentos que construian la línea partidaria, poniendo de manifiesto la lógica política que los anudaba. En tal sentido, el papel de la legalidad fue muy importante porque permitió al PC justificar la línea y, al mismo tiempo, preservar la organización. Dicho de otro modo, la legalidad permitía demostrar, ante propios y ajenos, que los militares no eran un bloque monolitico y que el sector que lideraba el "Proceso" no era el más peligroso para el pueblo. Al contrario, quienes deseaban el bienestar de todos, entre los cuales claramente no se encontraban las organizaciones armadas, debían colaborar en la preservación del gobierno. Pero además, la legalidad se transformó en el eje de las prácticas del partido en aquellos años. Así, les permitió realizar una serie de gestiones que ayudaron a preservar a los comunistas de la represión y a rescatar a numerosos militantes que, no obstante, eran detenidos o secuestrados a diario. Sin embargo, este artículo también intentó mostrar que la legalidad, como argumento y como práctica política, era inestable y dependia, en buena medida, de la voluntad de las Fuerzas Armadas a nivel local. Así, las rivalidades inter e intra fuerzas fueron decisivas en la forma y extensión que adoptó la represión en cada región.

Finalmente, el trabajo mostró cómo la disciplina partidaria y las formas de construcción de estilo estalinista fueron mecanismos importantes que explican, al menos en parte, el sostenimiento de la línea a lo largo del tiempo. En tal sentido, la percepción de la realidad se encontraba fuertemente mediatizada por los análisis oficiales de la dirección que tendian a reproducirse hasta el cansancio y en contra de lo que ocurría diariamente. Los responsables locales solian reducir los desacuerdos a "falencias en la comprensión de la línea", "sectarismos" o "prejuicios antimilitaristas" y obliteraban la posibilidad de revisar las caracterizaciones. Lo que es peor, minimizaban u ocultaban situaciones en las que podia correr riesgo la vida. Pero en el PC, la educación en torno a la infalibilidad de los dirigentes era un elemento constitutivo de sus prácticas $\mathrm{y}$, si no se insiste suficientemente en este aspecto, no es posible comprender cómo, a pesar del paso del tiempo, la mayoría de los militantes continuó dentro del partido.

En suma, algunos lectores aun podrán preguntarse: ¿cómo es posible que un partido que se autodenominaba de izquierda haya acompañado a la dictadura más cruenta de la historia argentina? En este artículo hemos intentado dar una respuesta y señalar que la explicación debe hallarse en la propia política del PC entendida en un sentido amplio, en sus principios teóricos rectores, su política de alianzas y también su cultura interna. Un modo de ser y funcionar que frente a una lectura oficial, a todas luces equivocada, fue incapaz de reaccionar para torcer el rumbo y prefirió creer. 


\section{Bibliografia}

Arévalo, Oscar, (1983), El Partido Comunista, Buenos Aires: CEAL.

Casola, Natalia (2011) "Cuando lo «nuevo» es tan «viejo» como «nuevo» lo «viejo». El movimiento de derechos humanos durante la última dictadura militar en Argentina. El papel del Partido Comunista de Argentina y la Liga Argentina por los Derechos del Hombre (1976-1983)", en História Oral, vol. 1, $\mathrm{N}^{\circ} 14$.

- (2012), Estrategia, militancia y represión. El Partido Comunista de Argentina durante la última dictadura militar (1976-1983)", tesis doctoral, Facultad de Filosofia y Letras, 2012, mimeo.

Codovilla, Victorio (1964), Una trayectoria consecuente, 2da. edición, tomo IV, Buenos Aires: Editorial Anteo.

Brega, Jorge (1990), El maoísmo en la Argentina. Conversaciones con Otto Vargas, Buenos Aires: Agora.

Campione, Daniel (1996), "Los comunistas argentinos. Bases para reconstruir su historia", en Periferias, año I, $\mathrm{N}^{\circ} 1$, segundo semestre.

- (2005), "Hacia la convergencia cívico-militar. El Partido Comunista 19551976", en Herramienta, N²9.

- (2012), "El Partido Comunista de Argentina y el golpe de Estado de 1976", disponible en http://www.rebelion.org/docs/24748.pdf. Consulta: $12 / 7 / 2012$.

Echagüe, Carlos (1986), El socialimperialismo ruso en la Argentina, Buenos Aires: Agora, 2da. edición.

Fava, Athos (1982), ¿Qué es el Partido Comunista?, Buenos Aires: Sudamericana.

Gilbert, Isidoro (1994), El oro de Moscú, Buenos Aires: Sudamericana.

- (2009), La Fede, Buenos Aires: Sudamericana.

Lamberto, Sofia (2006), El largo amorío de la última dictadura argentina con la URSS (Parte I), disponible en http:/ / www.debatecultural.org/Observatorio/SofiaLamberto.htm. Consulta: 12/7/2012.

Reato, Ceferino (2012), Disposición final. La confesión de Videla sobre los desaparecidos, Buenos Aires: Sudamericana.

$$
* * *
$$

Resumen: El presente artículo examina la actuación del PC durante la última dictadura militar. En primer lugar, el trabajo busca vincular la orientación oficial de los comunistas, el apoyo "táctico" al gobierno de J. R. Videla y el llamado a la "convergencia cívico militar", con la política histórica del partido sustentada en la idea de revolución por etapas. En segunda instancia el artículo se detiene en la materialización práctica de esas definiciones, en el papel de la legalidad y en la relación con las Fuerzas Armadas. Finalmente, la investigación analiza el lugar de la disciplina partidaria como factor que permite explicar, al menos en parte, la persistencia de la línea oficial, sostenida contra la propia realidad: 
la extensión del sistema de terror por encima de las rivalidades existentes al interior de las Fuerzas Armadas.

Palabras clave: Partido Comunista - dictadura militar - convergencia cívico militar

Abstract: This paper deals with the role played by the Communist Party of Argentina during the last military dictatorship. First, the article seeks to link the official Communist Party positions during those years, the "tactical support" for the government of J. R. Videla and the call for a "civic-military convergence", with the historical party line, based on the idea of revolution in stages. Secondly, the article examines the practical realization of these definitions, the role of legality and the relationship with the Armed Forces. Finally, the paper explores the place of party discipline as a factor that explains, at least in part, the persistence of the official line, sustained even against reality: the extension of the system of terror over existing rivalries within the Armed Forces.

Keywords: Argentine Communist Party - military dictatorship - civilian-military convergence

Recepción: 29 de diciembre de 2012. Aprobación: 18 de marzo de 2013. 